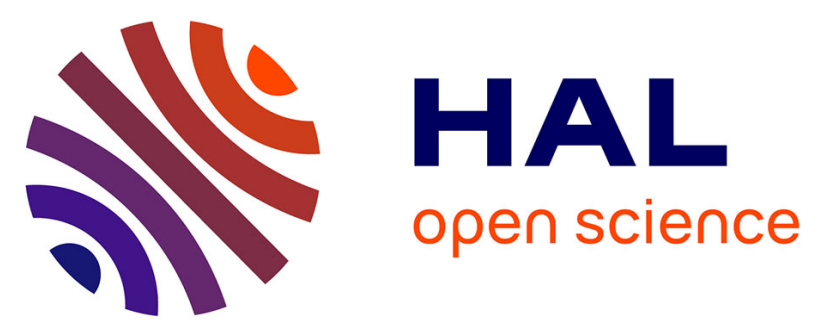

\title{
Letter to the editor Resolution of bortezomib-associated chalazia/blepharitis after switch to ixazomib: a case report
}

Jean Lemoine, Agnes Bonnin, Zora Marjanovic, Zoé van de Wyngaert, Souhila Ikhlef, Tamim Alsuliman, Fella M 'Hammedi-Bouzina, Mohamad Mohty,

Florent Malard

\section{To cite this version:}

Jean Lemoine, Agnes Bonnin, Zora Marjanovic, Zoé van de Wyngaert, Souhila Ikhlef, et al.. Letter to the editor Resolution of bortezomib-associated chalazia/blepharitis after switch to ixazomib: a case report. Current Research in Translational Medicine, 2021, 69 (2), pp.103283. 10.1016/j.retram.2021.103283 . hal-03154563

\section{HAL Id: hal-03154563 \\ https://hal.sorbonne-universite.fr/hal-03154563}

Submitted on 1 Mar 2021

HAL is a multi-disciplinary open access archive for the deposit and dissemination of scientific research documents, whether they are published or not. The documents may come from teaching and research institutions in France or abroad, or from public or private research centers.
L'archive ouverte pluridisciplinaire HAL, est destinée au dépôt et à la diffusion de documents scientifiques de niveau recherche, publiés ou non, émanant des établissements d'enseignement et de recherche français ou étrangers, des laboratoires publics ou privés. 


\section{Corresponding author:}

\section{Letter to the editor} report work.

Resolution of bortezomib-associated chalazia/blepharitis after switch to ixazomib: a case

Jean Lemoine, Agnes Bonnin, Zora Marjanovic, Zoe van de Wyngaert, Souhila Ikhlef, Tamim Alsuliman, Fella M 'Hammedi-Bouzina, Mohamad Mohty, Florent Malard

${ }^{1}$ Service d'Hématologie Clinique et Thérapie Cellulaire, Hôpital Saint-Antoine, Sorbonne Université, INSERM UMRs 938, Paris, France

Dr F. Malard, Service d'Hématologie Clinique et Thérapie Cellulaire, Hôpital Saint-Antoine, Paris, France. Email: florent.malard@inserm.fr, Phone: +3314928 2620

Keywords: multiple myeloma, chalazia, blepharitix, ixazomin, bortezomib

\section{Disclosure of Conflicts of Interest}

Tamim Alsuliman reports honorarium from Biotest France SAS outside the submitted work. Mohamad Mohty reports grants and/or lecture honoraria from Janssen, Sanofi, MaaT Pharma, JAZZ Pharmaceuticals, Celgene, Amgen, BMS, Takeda, Pfizer, and Roche outside the submitted work. Florent Malard reports lecture honoraria from Therakos/Mallinckrodt, Biocodex, Janssen, Keocyt, Sanofi, Jazz Pharmaceuticals, and Astellas outside the submitted work. The other authors did not disclose any relevant conflict of interest in relation to this 


\section{Introduction}

30 Bortezomib is a first-generation proteasome inhibitor approved by the US Food and Drug Administration (FDA) and the European Medical Agency (EMA) for the treatment of multiple myeloma (MM) at diagnosis and in relapsed or refractory disease [1,2]. Bortezomib is widely used in first-line treatment as part of a three-drug induction regimen before autologous hematopoietic cell transplantation in young patients [3] or combined with melphalan and prednisone in older patients [4]. Common adverse effects include fatigue, gastrointestinal disturbances, peripheral neuropathy, thrombocytopenia and herpes zoster infection [5,6]. Ocular adverse effects of bortezomib are less well known. Recently, some case reports have shed light on the association between eyelid chalazia/blepharitis and bortezomib therapy [7-10]. Chalazia is defined as the swelling of the eyelid margin as a result of a lipogranulomatous collection in the meibomian glands. Blepharitis is an inflammatory condition of the eyelid margin. Topical management of chalazia/blepharitis consists of the application of warm compresses together with eyelid hygiene and massage to promote drainage of the occluded gland duct. Combination with anti-inflammatory or antibiotic eye drops can also be useful [11]. Severe cases may require systemic antibiotics or even surgical incision and drainage. While chalazia/blepharitis is not a life-threatening complication, it can severely impair a patient's quality of life. We report herein the case of a bortezomib induced chalazia/blepharitis, resistant to conservative treatment but which resolved after switching to ixazomib, an oral proteasome inhibitor $[12,13]$.

\section{Observation}

An 87-year old man was referred to the hematology department with MM. First-line treatment consisted of 9 cycles of lenalidomide-dexamethasone. Due to disease progression a few months after the end of this first-line therapy, a new treatment was initiated consisting of 6 cycles of 6 weeks of bortezomib $1.3 \mathrm{mg} / \mathrm{m} 2$ on day $1,8,15$, and 22 combined with oral melphalan $0.2 \mathrm{mg} / \mathrm{kg} /$ day and oral prednisone $1 \mathrm{mg} / \mathrm{kg} /$ day both from day 1 to 4 . Serum monoclonal protein was undetectable after 2 cycles of this therapeutic regimen. During the third cycle, the patient developed eyelid inflammation. The ophthalmological exam confirmed the diagnosis of bilateral chalazia/blepharitis with right predominance, in the context of bortezomib treatment (Figure 1). Prolonged eyelid hygiene associated with topical treatment by oxytetracycline/dexamethasone for 1 month was unsuccessful. In order to minimize patient visits to the hospital during the COVID-19 outbreak, bortezomib was switched for ixazomib, a second-generation proteasome inhibitor administered orally at home [14]. Ixazomib $2.3 \mathrm{mg}$ was given orally on day 1, 8, 15, and 22 combined with unchanged oral melphalan and prednisone treatment (cycles of 6 weeks). This regimen was adapted from the protocol published by San Miguel et al. where ixazomib was given on day 1, 8, 22, and 29 [15]. We decided to use a reduced dose of ixazomib given the age of the patient ( 87 years) and the fact that he was already in complete response, to reduce the risk of side effects, in particular thrombopenia [16]. Bortezomib 
discontinuation for ixazomib led to complete resolution of observed ocular symptoms within 2 weeks

(Figure 2). Symptom resolution allowed topical treatment cessation without relapse of ocular manifestations. Following this therapy switch, the monoclonal protein remained undetectable during the 3 months follow-up.

\section{Discussion}

In 2019, chalazia/blepharitis were added to the list of bortezomib side effects considering the EMA's pharmacovigilance risk assessment committee (PRAC) report for this therapy. In most cases, these ocular side effects were refractory to first-line conservative treatment, associated eyelid hygiene and anti-inflammatory and/or antibiotic eye drops, instead requiring incision and drainage. Recently, case reports of successfully treated bortezomib-induced blepharitis with oral doxycycline in combination with topical antibiotics have been reported, allowing continuation of bortezomib [17]. In 2019, Sklar and colleagues proposed a treatment algorithm for such eyelid complications, limiting use of incision and drainage [18].

We report here, several arguments supporting the relationship between ocular symptoms and the intake of bortezomib: First, the patient has no history of chalazia/blepharitis and this condition developed during the third cycle of chemotherapy, which is consistent with the other case reports showing that symptoms appear most frequently after 2-3 bortezomib cycles. Moreover, severe blepharitis with multiple chalazia, resistant to prolonged topical treatment, was resolved after bortezomib discontinuation.

The biological mechanism by which bortezomib could cause chalazia/blepharitis is poorly understood but is postulated to be related to inflammation. Bortezomib is a proteasome inhibitor targeting the ubiquitin-proteasome pathway leading to the accumulation of proapoptotic molecules and apoptosis of malignant cells. One can hypothesize that accumulation of degraded proteins in the meibomian glands may support bortezomib-associated ocular complications. Bortezomib may also induce a systemic inflammatory signature as it modulates critical cellular pathways such as NF-kB [19]. Interestingly, it has been reported, in one patient, that blepharitis had resolved while receiving $40 \mathrm{mg}$ of intravenous dexamethasone but flared secondarily when the dose was decreased to $10 \mathrm{mg}$, supporting the proinflammatory hypothesis [18]. Moreover, rash is a well-known side effect of bortezomib, with an incidence in clinical trials ranging from $8 \%$ to $18 \%$ [20]. The skin and the eyelids, including the meibomian glands, may have in common certain molecules targeted by bortezomib. VigiBase is a world health organization (WHO) global database of individual case safety reports. When screening VigiBase for the three proteasome inhibitors approved and routinely used in clinical settings, bortezomib, carfilzomib and ixazomib [21], they are all associated with side effects of the ocular spectrum. For example, reports concerning ixazomib showed increased lacrimation, eyelid disorder, eyelid rash, eyelid ptosis, swelling of eyelid, eyelid margin crusting, eyelid oedema, and 
103 meibomian gland dysfunction. As bortezomib was the first proteasome inhibitor developed it is

104 probable that post-authorization safety studies and case reports are overrepresented in the literature

105 compared with carfilzomib and ixazomib. Most of the time, ocular toxicity is not a cross-toxicity

106 among proteasome inhibitors resulting in symptom resolution after therapy switch, even if

107 chalazia/blepharitis can occur with the different molecules of this therapeutic class. In this case report,

108 we cannot rule out the possibility that the low dose of ixazomib used prevented development of ocular

109 complications, even if the dose-effect relationship of such adverse effects has not been established.

110 Even if ocular complications associated with proteasome inhibitors are not life-threatening, it can

111 severely impair a patient's quality of life. The majority of bortezomib-associated chalazia/blepharitis

112 are resistant to prolonged topical treatment and may be attenuated by oral doxycycline. If these

113 strategies are not sufficient, proteasome inhibitor switch may enable symptom resolution in some

114 cases as reported herein.

115

\section{Acknowledgment}

117 We would like to thank our medical team, nurses, patients family for their dedicated patients care and 118 continuous support.

119

120 Informed consents

121 Informed consents were obtained from the patient for the publication of the case.

122

123

124

125 


\section{References}

1271 Jagannath S, Durie BGM, Wolf J, Camacho E, Irwin D, Lutzky J, et al. Bortezomib therapy alone and in combination with dexamethasone for previously untreated symptomatic multiple myeloma. Br J Haematol. juin 2005;129(6):776-83.

1302 Richardson PG, Barlogie B, Berenson J, Singhal S, Jagannath S, Irwin D, et al. A Phase 2 Study of Bortezomib in Relapsed, Refractory Myeloma. N Engl J Med. 26 juin 2003;348(26):2609-17.

3 Mohty M, Malard F, Bazarbachi A. Bortezomib, Lenalidomide and Dexamethasone as Induction Therapy Prior to Autologous Transplantation in Multiple Myeloma: The More Is Likely the Better. Clin Hematol Int. mai 2020;2(2):92-3.

4 Mateos M-V, Richardson PG, Schlag R, Khuageva NK, Dimopoulos MA, Shpilberg O, et al. Bortezomib plus melphalan and prednisone compared with melphalan and prednisone in previously untreated multiple myeloma: updated follow-up and impact of subsequent therapy in the phase III VISTA trial. J Clin Oncol Off J Am Soc Clin Oncol. 1 mai 2010;28(13):2259-66.

5 Scott K, Hayden PJ, Will A, Wheatley K, Coyne I. Bortezomib for the treatment of multiple myeloma. Cochrane Database Syst Rev. 20 avr 2016;4:CD010816.

1416 Vij R. Treatment-related adverse events in patients with relapsed/refractory multiple myeloma. Oncol Williston Park N. 15 nov 2011;25 Suppl 2:45-55.

Fraunfelder FW, Yang HK. Association Between Bortezomib Therapy and Eyelid Chalazia. JAMA Ophthalmol. 1 janv 2016;134(1):88.

8 Grob SR, Jakobiec FA, Rashid A, Yoon MK. Chalazia Associated with Bortezomib Therapy for Multiple Myeloma. Ophthalmology. sept 2014;121(9):1845-1847.e3.

9 Laaribi N, Abdellaoui T, Abaloun Y, Fiqhi A, Rabii H, Haidouri S, et al. Chalazia associated with bortezomib therapy. J Fr Ophtalmol. oct 2018;41(8):e381-2.

10 Yun C, Mukhi N, Kremer V, Shinder R, Verma V, Batuman O. Chalazia development in multiple myeloma: a new complication associated with bortezomib therapy. Hematol Rep [Internet]. 9 juin 2015 [cité 18 mai 2020];7(2). Disponible sur: http://www.pagepress.org/journals/index.php/hr/article/view/5729

11 Duncan K, Jeng BH. Medical management of blepharitis. Curr Opin Ophthalmol. juill 2015;26(4):289-94.

12 Kupperman E, Lee EC, Cao Y, Bannerman B, Fitzgerald M, Berger A, et al. Evaluation of the 2010;70(5):1970-80.

13 Moreau P, Masszi T, Grzasko N, Bahlis NJ, Hansson M, Pour L, et al. Oral Ixazomib, 2016;374(17):1621-34.

16114 Malard F, Mohty M. Management of patients with multiple myeloma during the COVID-19 pandemic. Lancet Haematol. 2020;7(6):e435-7. 
16616 Richardson PG, Zweegman S, O’Donnell EK, Laubach JP, Raje N, Voorhees P, et al. Ixazomib 167 for the treatment of multiple myeloma. Expert Opin Pharmacother. 22 nov 2018;19(17):1949-68.

16817 Veys M-C, Delforge M, Mombaerts I. Treatment With Doxycycline for Severe Bortezomib-

169 Associated Blepharitis. Clin Lymphoma Myeloma Leuk. juill 2016;16(7):e109-12.

17018 Sklar BA, Gervasio KA, Leng S, Ghosh A, Chari A, Wu AY. Management and outcomes of 171 proteasome inhibitor associated chalazia and blepharitis: a case series. BMC Ophthalmol. déc $172 \quad$ 2019;19(1):110.

17319 Sunwoo JB, Chen Z, Dong G, Yeh N, Crowl Bancroft C, Sausville E, et al. Novel proteasome inhibitor PS-341 inhibits activation of nuclear factor-kappa B, cell survival, tumor growth, and angiogenesis in squamous cell carcinoma. Clin Cancer Res Off J Am Assoc Cancer Res. mai 2001;7(5):1419-28.

20 Reyes-Habito CM, Roh EK. Cutaneous reactions to chemotherapeutic drugs and targeted therapy for cancer: Part II. Targeted therapy. J Am Acad Dermatol. août 2014;71(2):217.e1-217.e11; quiz 227-8.

18021 Manasanch EE, Orlowski RZ. Proteasome inhibitors in cancer therapy. Nat Rev Clin Oncol. juill 2017;14(7):417-33. 


\section{$184 \quad$ Figure legends}

185

186 Figure 1: Clinical photograph showing blepharitis associated with multiple chalazia with right

187 predominance

188

189 Figure 2: Clinical photograph showing resolution of bortezomib associated chalazia/blepharitis after 190 switching to ixazomib

191 
192 Figure 1.

193
194

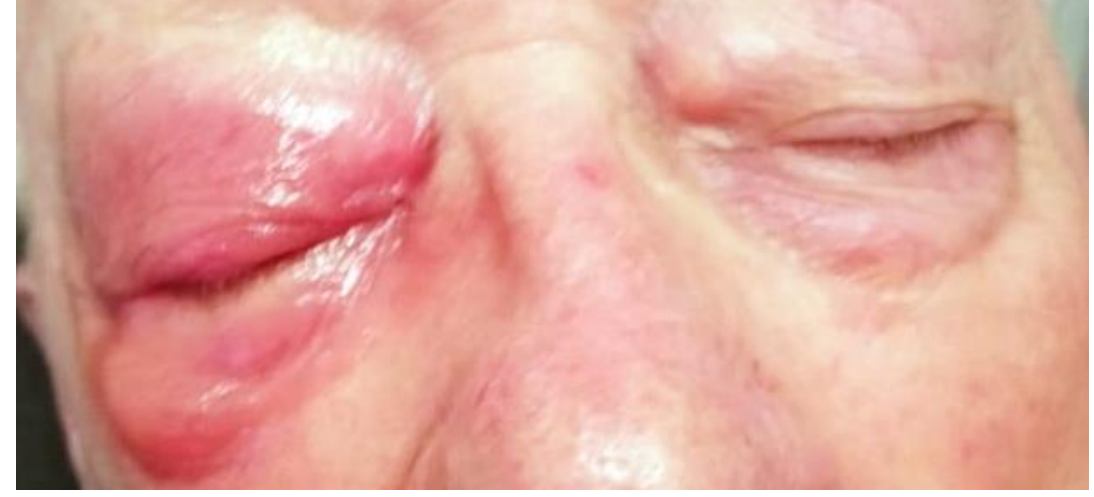


195 Figure 2.

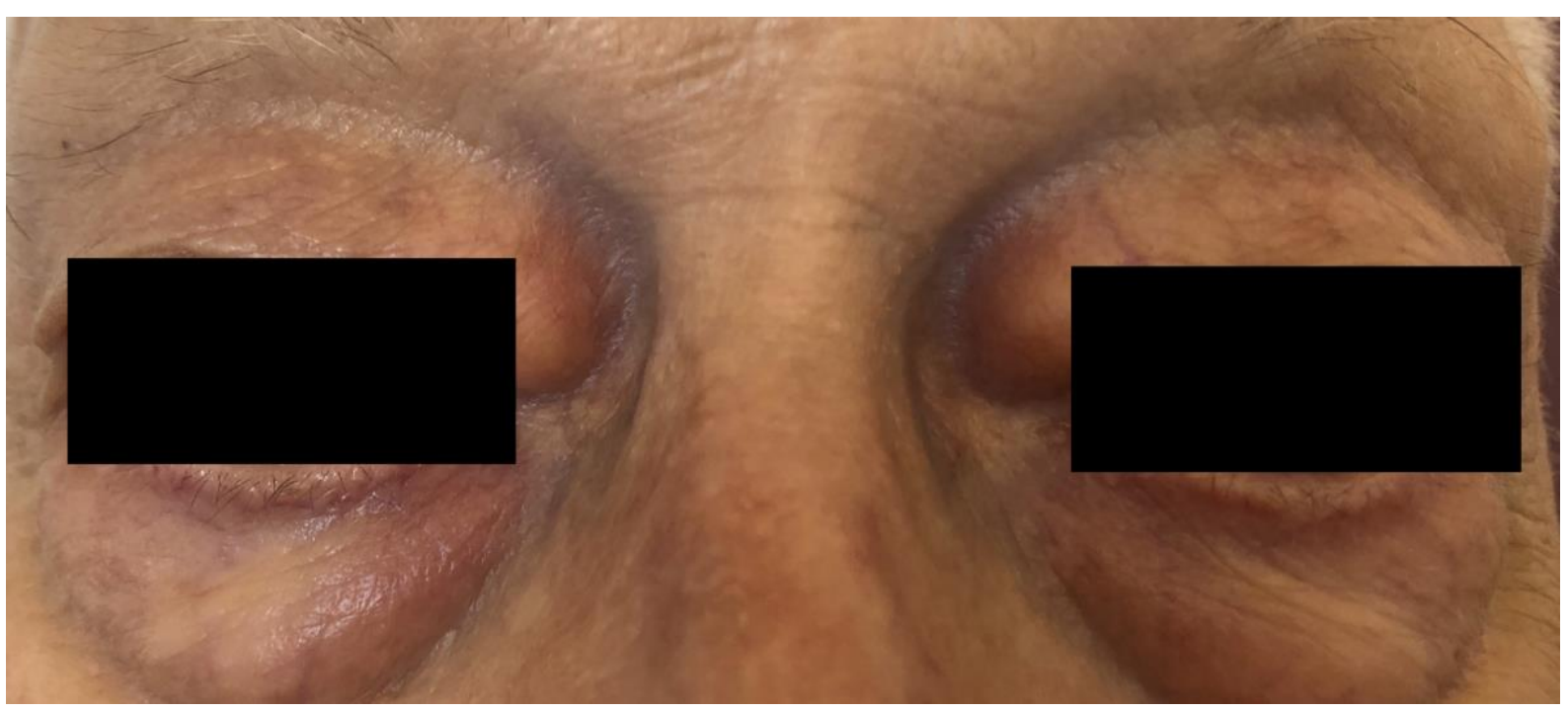

196 